\title{
ADDITIVE MANUFACTURING OF Ni36Co37AI27 FERROMAGNETIC SHAPE MEMORY MATERIAL USING MECHANICALLY ALLOYED PLASMA SPHEROIDIZED POWDERS
}

\author{
Artem KIM, Alina MAZEEVA, Igor POLOZOV, Aleksey SHAMSHURIN, Kirill STARIKOV, \\ Sergey IGOSHIN, Nikolay OZERSKOY, Anatoliy POPOVICH
}

Peter the Great St. Petersburg University, St. Petersburg, Russia, artem 7.kim@mail.ru

https://doi.org/10.37904/metal.2021.4241

\begin{abstract}
Currently, 3D-printing of smart materials is actively developing. Alloys based on intermetallic compounds Ni$\mathrm{Mn}-\mathrm{Ga}$ and Ni-Co-Al are of great interest due to the ability to manipulate their deformation behavior by external magnetic field with much higher effect than in conventional magnetostrictive materials. These materials can be used not only as sensors, but also as elements of smart structures and actuators of modern power drives. In this study we synthesized $\mathrm{Ni}_{36} \mathrm{C}_{37} \mathrm{Al}_{27}$ alloy by mechanical alloying with further plasma spheroidization and fabricated the samples by selective laser melting (SLM). Elemental $\mathrm{Co}, \mathrm{Ni}$ and Al powders were used as initial materials for mechanical alloying process. The influence of mechanical alloying parameters on the physical and chemical properties of the obtained materials was investigated. It was found that the low-energy mode of the planetary mill provides mixing of the alloy components with the least amount of impurity. The final spherical powders for 3D-printing were obtained by plasma spheroidization followed by separation of 10-40 $\mu \mathrm{m}$ fraction. Selective laser melting was used to fabricate samples from synthesized $\mathrm{Ni}_{36} \mathrm{CO}_{37} \mathrm{Al}_{27}$ powder. The obtained samples had a two-phase $\gamma+\beta$-structure with a density from 5.41 to $7.27 \mathrm{~g} / \mathrm{cm}^{3}$ and a hardness of up to 447 $\mathrm{HV}$. In the course of the work carried out, the most optimal modes for SLM printing from the $\mathrm{Ni}_{36} \mathrm{Co}_{37} \mathrm{Al}_{27}$ alloy were selected to obtain samples with maximal density under minimal ability to crack formation.
\end{abstract}

Keywords: Magnetic shape memory alloys, mechanical alloying, additive technologies, powder metallurgy, plasma spheroidization

\section{INTRODUCTION}

Shape memory alloys are gaining increasing interest as functional materials for a wide range of applications in industry and medicine. Among this group of materials, ferromagnetic shape memory alloys (FSMA) stand out due to their capability to demonstrate high deformations (6-8\%) and high response frequency under the influence of a magnetic field. Due to their unique properties, they are suitable for sensors, actuators, energy applications, biomedical applications [1].

The most studied FSMA systems are Ni-Mn-Ga (Heusler alloys).However, strong brittleness in the polycrystalline state and high cost significantly limit the practical application of these alloys. In this regard, more and more attention is attracted by nonstoichiometric two-phase ( $\beta$ and $\gamma$ ) systems based on Ni-Co-Al. These alloys have good ductility, low cost and availability of elements.

Under the action of a magnetic field, the $\beta$-phase undergoes a thermoelastic martensitic transformation from B2-austenite (cubic) to twinned martensite of the L10 type (tetragonal), which is accompanied by deformation. The presence of the second phase can significantly increase the ductility and workability of the material. Depending on the concentration of $\mathrm{Ni}$ and $\mathrm{Co}$ and different conditions of heat treatment, the $\mathrm{Y}(\mathrm{A} 1)$ or $\mathrm{Y}^{\prime}\left(\mathrm{L} \mathrm{1}_{2}\right)$ phase is precipitated, which have different mechanical properties [2]. The optimal composition to achieve appropriate functional and mechanical properties lies in a near-equiatomic ratio [3]. The authors [4] demonstrated the dependence of the temperature of the beginning and end of the phase transformation 
$\beta \rightarrow L 10$, as well as the Curie temperature on the chemical composition of the alloy. It was found that small changes in Co concentration have a significant effect on the magnetic properties of the material.

One of the rapidly developing methods to produce metal products is additive manufacturing. The most technologically advanced methods to produce metallic parts is selective laser melting (SLM). However, the first and one of the most critical stages in additive manufacturing process is development of powders with the necessary chemical, physical, and technological properties. The production method (hydriding, mechanical attrition, water atomization, and gas atomization) determines the degree of purity, morphology, and size of the powders. One of the most universal methods to produce spherical powders of various composition and with defined particle distribution is plasma spheroidization (PS).

Since the feedstock material for this process is an initial powder of any irregular shape, it should have an appropriate chemical composition. Mechanical alloying (MA) is a comparatively simple and effective technique to obtain a powder of various compositions from pure raw elemental powders. The method of MA followed by PS was successfully applied for other metal alloys in [5].

The aims of this work were (a) to obtain a spherical powder $\mathrm{Ni}_{36} \mathrm{CO}_{37} \mathrm{Al}_{27}$ suitable for use in additive manufacturing by the methods of mechanical alloying and plasma spheroidization; (b) to print samples from the synthesized powder using the SLM method; (c) to investigate the structure and properties of the samples obtained; (d) to study the possibility of in-situ synthesis of $\mathrm{Ni}_{36} \mathrm{C}_{37} \mathrm{Al}_{27}$ alloy during the process of printing from pure Co and NiAl powders.

\section{MATERIALS AND METHODS}

The elemental powders (all of them 99.5\% purity) of Co $(50-150 \mu \mathrm{m}), \mathrm{Ni}(71-250 \mu \mathrm{m})$ and $\mathrm{Al}(40-63 \mu \mathrm{m})$ were mixed (weight $30 \mathrm{~g}$ ) to obtain the composition of 37Co-36Ni-27Al (at\%) and then mechanically alloyed using a planetary mill Fritsch Pulverisette 4 in argon atmosphere. Steel balls with a diameter of 10 and $20 \mathrm{~mm}$ and a total mass of $600 \mathrm{~g}$ were used as grinding media. MA parameters were 150-300 (rotation speed of the main disk/rotation speed of the cup around its axis), 200/400 and 200/600 rpm.

A dry grinding SD5 laboratory attritor produced by Union Process (USA) was used to produce a large powder batch by MA. The initial elemental powders were mixed to achieve the composition of the alloy and milled for $13 \mathrm{~h}$ using stainless steel grinding media in an argon atmosphere with the rotation speed of $270 \mathrm{rpm}$ and 20:1 ball to powder mass ratio.

Powders for additive manufacturing were produced using the Tekna TEK-15 (Tekna, Canada) plasma spheroidization unit. The $\mathrm{Ar}-\mathrm{H}_{2}$ gas was used as the plasma forming gas. The feed rate of the powders into the plasma was $60 \mathrm{~g} / \mathrm{min}$ and the plasma torch power was $15 \mathrm{~kW}$.

The MA and SP powders were printed using a SLM $280 \mathrm{HL}$ machine with two fiber lasers with $1.07 \mu \mathrm{m}$ wavelength and maximum power $400 \mathrm{~W}$ and $1 \mathrm{~kW}$. The bulk samples of $10 \times 10 \times 10 \mathrm{~mm}$ size were produced for further investigation. The printing process was performed in a high-purity argon atmosphere. The printing parameters are listed in Table 1.

Two powder alloys were chosen to study the in-situ synthesis: NiAl and pure Co (99.5\%). The powder mixture was prepared from the initial powders by mixing them in a tumbler mixer for $12 \mathrm{~h}$. The time of mixing was chosen so that to obtain a uniform distribution of elements in the mixture. The bulk samples were synthesized using the AconityMIDI SLM system. The system is equipped with $1000 \mathrm{~W}$ fiber laser with $1060 \mathrm{~nm}$ wavelength. The preheating temperature was $900^{\circ} \mathrm{C}$.

The morphology, microstructure, and chemical composition of the obtained powders and the bulk samples were studied using Mira3 Tescan scanning electron microscope with an EDX Oxford Instruments X-Max 80 energy dispersive detector for $\mathrm{X}$-ray spectroscopy. 
Table 1 Laser printing parameters used in this study

\begin{tabular}{|c|c|c|c|c|c|c|}
\hline & $\begin{array}{c}\text { Laser } \\
\text { power } \\
(\mathrm{W})\end{array}$ & $\begin{array}{c}\text { Scan speed } \\
(\mathrm{mm} / \mathrm{s})\end{array}$ & $\begin{array}{c}\text { Hatch } \\
\text { distance } \\
(\mathrm{mm})\end{array}$ & $\begin{array}{c}\text { Layer } \\
\text { thickness } \\
(\mathrm{mm})\end{array}$ & $\begin{array}{c}\text { Rotation angle } \\
\text { between layers } \\
(\text { degree })\end{array}$ & $\begin{array}{c}\text { Volume energy } \\
\text { density } \\
\left(\mathrm{J} / \mathrm{mm}^{3}\right)\end{array}$ \\
\hline SLM 280 HL & $180-300$ & $150-550$ & $0.06-0.12$ & 0.05 & 33 & $69.4-200$ \\
\hline AconityMIDI & 140 & $600-950$ & $0.10-0.12$ & 0.03 & 67 & $51.9-77.8$ \\
\hline
\end{tabular}

X-ray diffraction and X-ray phase analysis was carried out on a Bruker Advance D8 diffractometer in the range of angles from $30^{\circ}$ to $90^{\circ}$ with a step of $0.02^{\circ}$ and an exposure of 2 seconds at each step.

The particle size distribution of the powders was studied using a Fritsch Analysette 22 NanoTec plus laser diffraction unit. To calculate the particle size distribution, the Fraunhofer model was used. The Archimedes method was used to study the relative density of the samples. Microhardness was measured using Microhardness tester Buehler Micromet 5103.

\section{RESULTS AND DISCUSSION}

From the results of microstructural analysis, it was found that complete dissolution of elements in the process of MA occurs in 25 hours for mode 150/-300, 20 hours for mode 200/-400, and 15 hours for mode 200/-600 rpm. Table 2 shows the chemical composition of the synthesized powders. The presence of iron is caused by milling from steel balls in the process of MA. The smallest amount of grind is formed with the parameters of MA 150/-300 rpm. The EDS-maps (Figure 1) of the alloying elements in powder particles confirm that $\mathrm{Co}, \mathrm{Ni}$ and $\mathrm{Al}$ are distributed relatively homogeneous. Thus, we can conclude that MA according to mode 150/-300 rpm for 25 hours provides a minimum amount of grinding with complete dissolution of the elements.

Table 2 Chemical composition of the samples

\begin{tabular}{|c|c|c|c|c|c|}
\hline Sample & $\begin{array}{c}\text { Time } \\
\text { (hours) }\end{array}$ & $\begin{array}{c}\text { Co } \\
(\text { at\%) }\end{array}$ & $\begin{array}{c}\text { Ni } \\
(\text { at\%) }\end{array}$ & $\begin{array}{c}\text { Al } \\
\text { (at\%) }\end{array}$ & $\begin{array}{c}\text { Fe } \\
(\text { at\%) }\end{array}$ \\
\hline MA 150/-300 & 25 & $37.0 \pm 0.4$ & $36.2 \pm 0.4$ & $26.6 \pm 0.3$ & $0.3 \pm 0.1$ \\
\hline MA 200/-400 & 20 & $36.2 \pm 0.13$ & $36.3 \pm 0.7$ & $25.9 \pm 1.2$ & $1.6 \pm 0.8$ \\
\hline MA 200/-600 & 15 & $35.5 \pm 0.4$ & $36.0 \pm 0.4$ & $25.6 \pm 0.4$ & $2.9 \pm 0.5$ \\
\hline MA attritor & 13 & $37.3 \pm 0.6$ & $35.8 \pm 0.7$ & $26.5 \pm 1.0$ & $0.4 \pm 0.1$ \\
\hline PS & - & $37.7 \pm 0.4$ & $37.0 \pm 0.4$ & $25.0 \pm 0.2$ & $0.3 \pm 0.1$ \\
\hline SLM HL & - & $37.6 \pm 0.1$ & $36.3 \pm 0.1$ & $25.3 \pm 0.2$ & $0.8 \pm 0.1$ \\
\hline
\end{tabular}
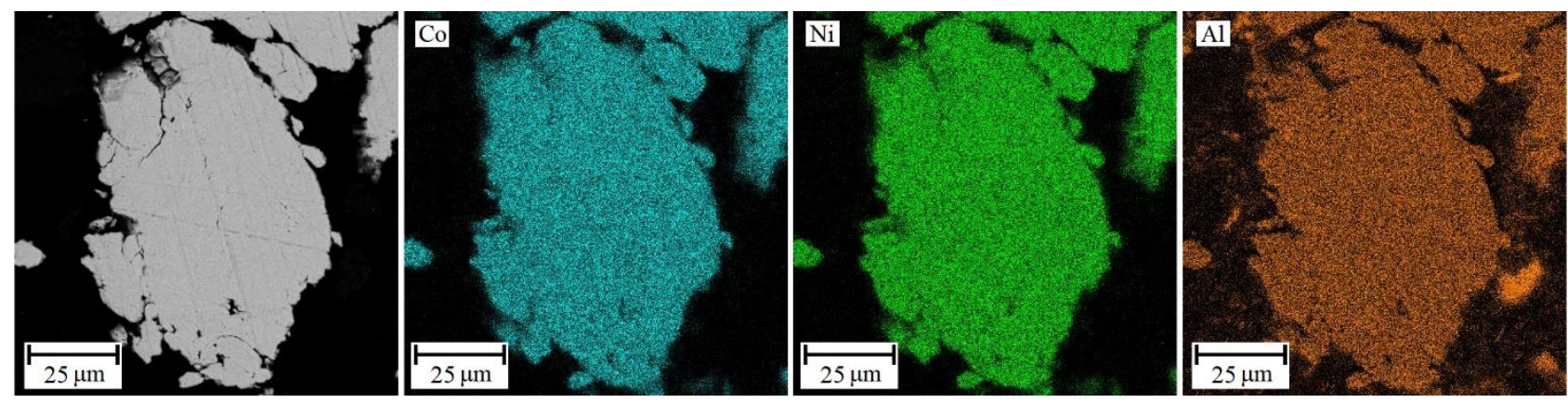

Figure 1 EDS mapping of the powder after MA 150/-300 for $25 \mathrm{~h}$

In this work, we also investigated the method of MA using an attritor. This method has a higher productivity compared to a planetary mill and can be used to produce powder for use in additive manufacturing. In a ball 
mill of the attritor type, due to the immobility of the container in which grinding occurs, the powder grinding mechanism is mainly implemented without shock effects. It has been established that at MA for 13 hours in the attritor, the elements are mixed similar to mode $150-300 \mathrm{rpm}$ in a planetary mill with a comparable $\mathrm{Fe}$ content. The chemical composition of the resulting powder is shown in the Table 1. Figure 2 shows the EDS maps of the powder after MA for 13 hours. It can be seen from the figures that the powder has a homogeneous structure with a uniform distribution of elements over the volume of particles.
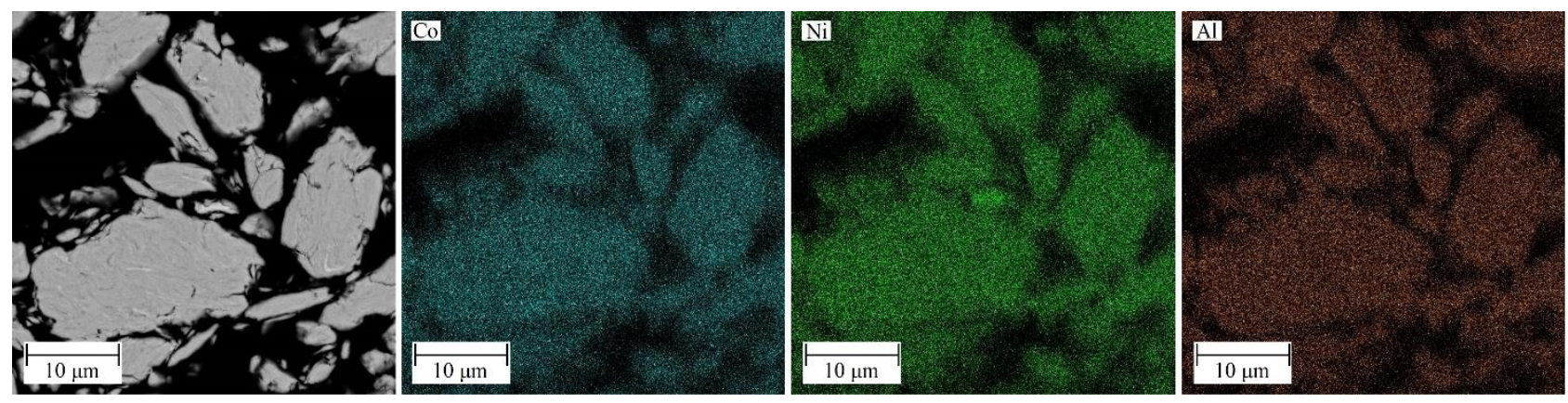

Figure 2 EDS mapping of the powder after MA in the attritor for $13 \mathrm{~h}$

Spheroidization of MA powder was carried out in a low-temperature plasma flow. A large number of submicron particles formed on the surface of the powder, which were removed by air classification followed by treatment in an ultrasonic bath. The morphology of the powder and distribution of elements is shown in Figure 3. It can be seen that the resulting powder is mainly spherical, but there are individual particles of irregular shape. The formation of aluminum oxide is observed on the surface of the particles. A noticeable decrease in the concentration of aluminum (Table 1 ) is probably due to its low boiling point and evaporation of aluminum during the PS of the alloy. The particle size of the final powder was $10-40 \mu \mathrm{m}$.
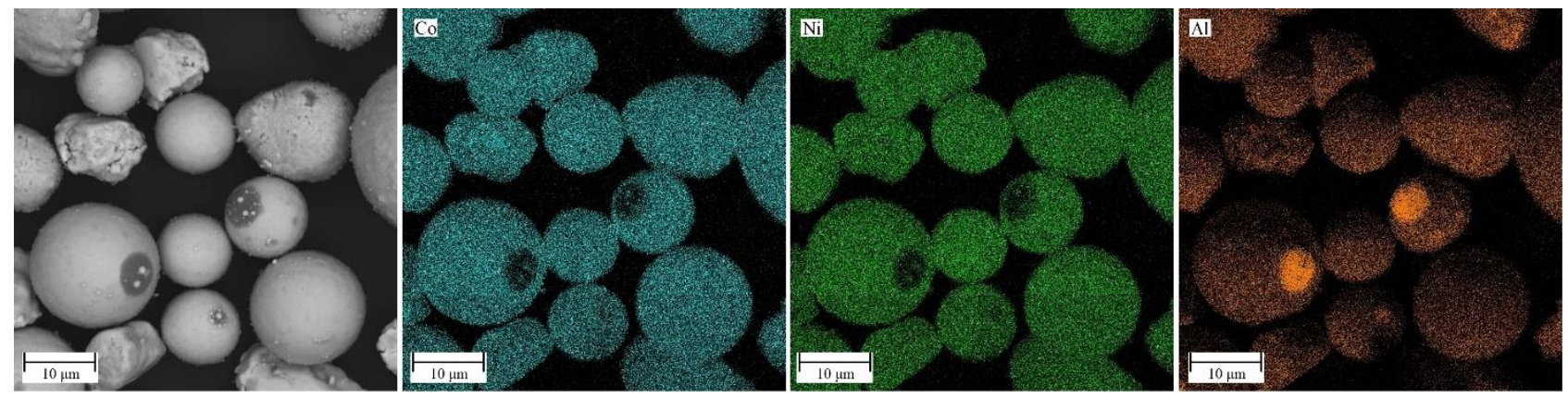

Figure 3 EDS mapping of the powder after PS

X-ray phase analysis of the synthesized powders (Figure 4) showed the presence of a y-phase with A1 structure and a $\beta$-phase with a B2 structure. The absence of peaks of the martensitic structure indicates that the point of the beginning of the martensitic transformation is below room temperature. In a micrograph of an etched section of a powder (Figure 4) obtained with an optical microscope, the $\mathrm{Y}$-phase looks like dark areas, and the $\beta$-phase - lightones. The phase ratio in the powder after treatment in a plasma jet was $21 \%$ of the $\beta$ phase and $79 \%$ of the $\mathrm{y}$-phase. The average grain size is 5 microns.

The XRD results (Figure 4) showed that the samples produced from SP powder have two-phase structure. The microstructure of the samples consists of dark grains of the $\beta$-phase, surrounded at the boundaries by the $Y$-phase. It was found that with an increase in the scanning speed, the samples are more prone to cracking during the SLM process, which is a result of higher cooling rates. On the other hand, high porosity was observed at a relatively low scan rate. These defects can be attributed to the entrapped gas originated from the raw material powders in the SLM process. In addition, aluminum due to low melting point may evaporate 
into gas to form gas bubbles. The gas bubbles do not have sufficient time to escape from the molten pool to the pool surface and remain within the molten pool to form porosity defects of a spherical shape [6].

a)
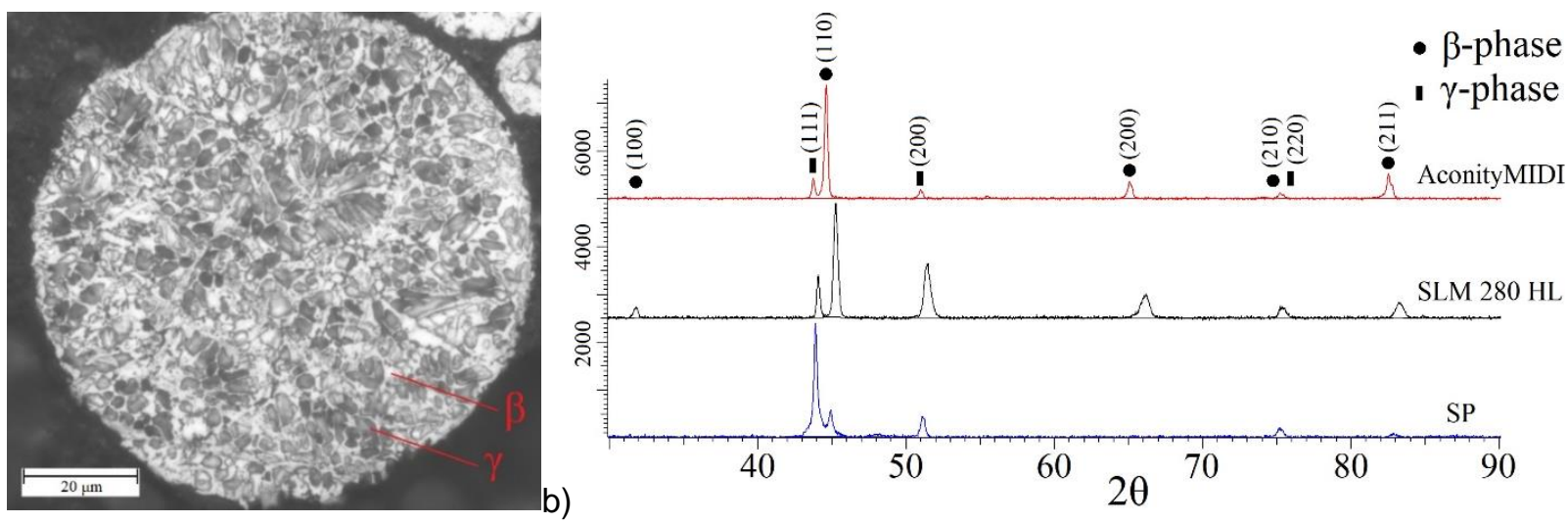

Figure 4 Micrograph of $\mathrm{Ni}_{36} \mathrm{Al}_{27} \mathrm{C}_{37}$ powder (a) after PS and (b) X-ray diffractogram after SP and SLM

The density of the obtained samples ranged from 5.41 to $7.27 \mathrm{~g} / \mathrm{cm}^{3}$. The measured microhardness of the samples was in the range from 396 to $447 \mathrm{HV}$. The pores are mostly spherical, which suggests that these are gas pores. The gas pores might originate from different sources such as entrapped protective gas, melt vaporization or pores inside the powder particles [7]. The highest density was achieved at laser power laser power $225 \mathrm{~W}$, scan speed $250 \mathrm{~mm} / \mathrm{s}$ and hatch distance $0.12 \mathrm{~mm}$, with microstructure with the least amount of visible defects. Flat tensile specimens produced according to these printing parameters showed a tensile strength of $510 \mathrm{MPa}$.

The Figure 5 shows the results of EBSD analysis of samples in the build direction. Difference is only in hatch distance and scan speed parameters. In the sample with the larger hatch distance, the grains are elongated in the direction perpendicular to the bath surface, which is explained by the sequential crystallization parallel to the direction of heat removal. In the sample with a smaller hatch distance, no dendritic structure is observed, which is probably due to the thermal effect of the nearest tracks.

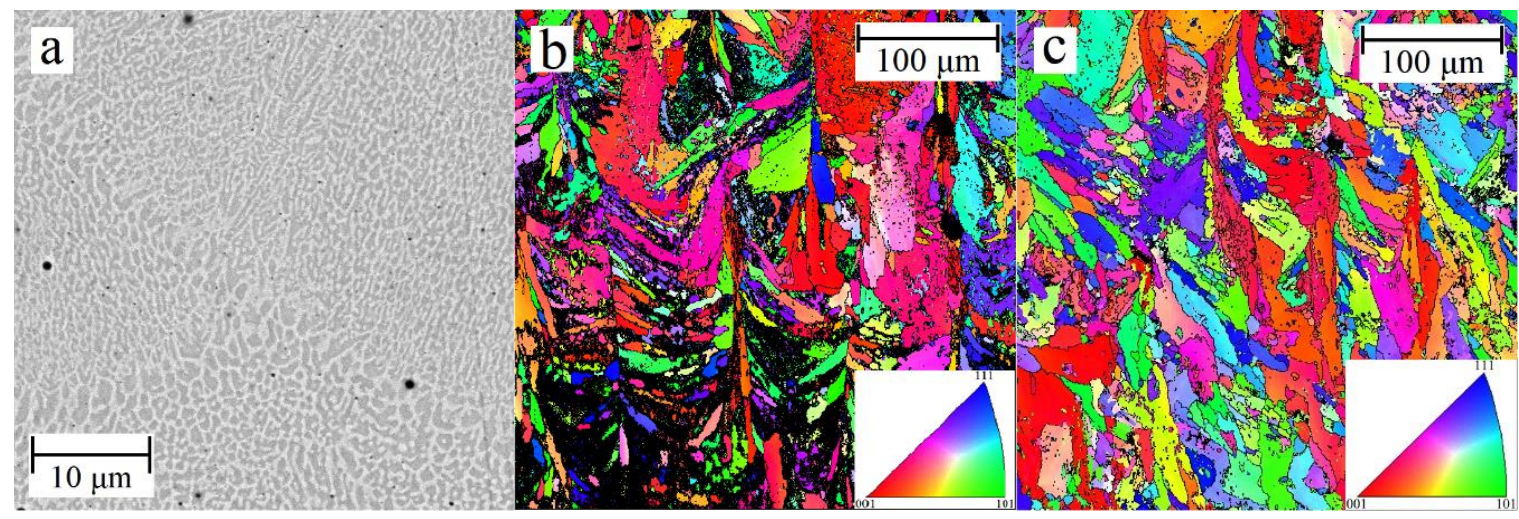

Figure 5 Microstructure of sample prepared by SLM (a). Printing parameter: laser power $225 \mathrm{~W}$, (b) hatch distance $0.12 \mathrm{~mm}$, scan speed $250 \mathrm{~mm} / \mathrm{s}$ and (c) distance $0.06 \mathrm{~mm}$, scan speed $500 \mathrm{~mm} / \mathrm{s}$

The composition of samples obtained by in-situ synthesis is characterized byy- and $\beta$-phases (Figure 4). SEM images of the microstructure (Figure 6) show a large amount of undissolved Co. Raising the volume energy density (VED) should lead to better dissolution of the elements in the alloy. The porosity of the samples ranged from 3.8 to $13.1 \%$. 

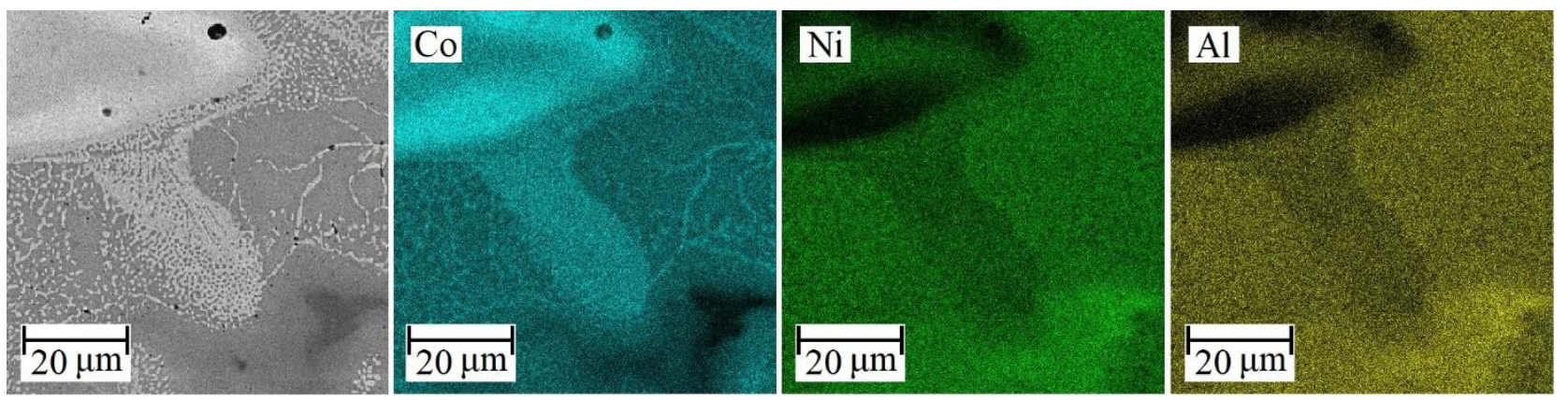

Figure 6 EDS mapping of the powder after PS

The lowest porosity (3.8\%) was at the following print parameters: laser power $140 \mathrm{~W}$, scan speed $600 \mathrm{~mm} / \mathrm{s}$, hatch distance $0.1 \mathrm{~mm}$, layer thickness $0.05 \mathrm{~mm}$.

\section{CONCLUSION}

In this study, a spherical $\mathrm{Ni}_{36} \mathrm{C}_{37} \mathrm{~A}_{127}$ alloy powder was produced from elemental powders by mechanical alloying and plasma spheroidization. The resulting powder with a fraction of 10-40 $\mu \mathrm{m}$ had a two-phase $\gamma+\beta$ structure. The parameters of printing parts from synthesized powder on the SLM $280 \mathrm{HL}$ machine were optimized. The resultant samples possess a tensile strength of $510 \mathrm{MPa}$ and a microhardness of up to 447 $\mathrm{HV}$. The density of the samples ranged from 5.41 to $7.27 \mathrm{~g} / \mathrm{cm}^{3}$. The structure and phase composition of the produced samples was investigated. The possibility of in-situ synthesis of $\mathrm{Ni}_{36} \mathrm{Co}_{37} \mathrm{Al}_{27}$ alloy from pure Co powder and NiAl alloy was studied. The minimum porosity of the samples was $3.8 \%$.

\section{ACKNOWLEDGEMENTS}

\section{This research was supported by the Russian Science Foundation grant (Project No. 20-79-00061).}

\section{REFERENCES}

[1] JU, J., XUE, F., ZHOU, J., BAI, J., SUN, L. Microstructure and mechanical properties change by rare earth Dy added in as-cast Co-Ni-Al ferromagnetic shape memory alloys. Materials Science and Engineering: $A$. [online]. 2014, vol. 616, pp. 196-200. Available from: https://doi.org/10.1016/j.msea.2014.08.033.

[2] KAINUMA, R., ISE, M., JIA, C.-C., OHTANI, H., ISHIDA, K. Phase equilibria and microstructural control in the NiCo-Al system. Intermetallics. [online]. 1996, vol. 4, pp.151-158. Available from: https://doi.org/10.1016/09669795(96)00034-9.

[3] TANAKA,Y., OHMORI,T.,OIKAWA, K., KAINUMA, R., ISHIDA, K. Ferromagnetic Co-Ni-Al shape memory alloys with $\beta+\gamma$ two-phase structure, Materials Transactions. [online]. 2004, vol. 45, pp. 427-430. Available from: https://doi.org/10.2320/matertrans.45.427.

[4] OIKAWA, K., WULFF, L., IIJIMA, T., GEJIMA, F., OHMORI, T., FUJITA, A., et al. Promising ferromagnetic NiCo-Al shape memory alloy system. Applied Physics Letters. [online]. 2001, vol. 79, pp. 290-3292. Available from: https://doi.org/10.1063/1.1418259.

[5] GONCHAROV, I., RAZUMOV, N., SHAMSHURIN, A., WANG, Q. Effect of the mechanical alloying and spark plasma sintering on microstructure. Phase composition and chemical elements distribution of $\mathrm{Nb}-\mathrm{Si}$ based composite. Key Engineering Materials. [online]. 2019, vol. 822, pp. 617-627. Available from: https://doi.org/10.4028/www.scientific.net/KEM.822.617.

[6] ZHANG, B., LI, Y., BAI, Q. Defect formation mechanisms in selective laser melting: A review. Chinese Journal of Mechanical Engineering. [online]. 2017, vol. 30, pp. 515-527. Available from: https://doi.org/10.1007/s10033-0170121-5.

[7] VOISIN, T., CALTA, N. P., KHAIRALlAH, S.A., FORIEN, J.-B., BALOGH, L., CUNNINGHAM, R.W. et al. Defectsdictated tensile properties of selective laser melted Ti-6Al-4V. Materials \& Design. [online]. 2018, vol. 158, pp. 113-126. Available from: https://doi.org/10.1016/j.matdes.2018.08.004. 